\title{
PowerPoint to the People: The Four Secrets to Delivering a Great Medical Talk
}

\author{
Alex Zhornitskiy ${ }^{1}$ - Alexander Nguyen ${ }^{2}$. Jonathan D. Kaunitz ${ }^{3}$
}

Published online: 25 April 2020

(c) Springer Science+Business Media, LLC, part of Springer Nature 2020

\begin{abstract}
Medical talks are a staple of post-medical school education, but the effectiveness of these lectures can be quite variable. One significant reason for this is that while physicians and trainees are well trained at presenting information to one another, they have little to no formal training on giving hour-long medical didactics. Focusing on four specific categories including creating a strong first impression, effective use of PowerPoint, impactful delivery of information, and thorough preparation a physician at any stage in training can become a strong presenter.
\end{abstract}

\section{Introduction}

Since completing medical school, physicians have attended hundreds, some even thousands, of medical talks. These include journal clubs, noon conferences, morbidity and mortality discussions, morning reports, weekly fellow didactics, and national conference presentations. Think back to the last talk that you have been to whether today, this week, or almost assuredly in the past month. What did you learn? Try and recall three concepts from that talk. It is challenging, but not surprising that recall is often limited [1]. Though easy to blame faulty memory or passing distractions, a likely culprit may have been the presentation itself.

There is no question regarding the necessity for scheduling regular medical lectures in the hospital setting. This format allows for in-person teaching in a time-efficient manner on topics that simply cannot be delved into brief, curbside discussions in hospital hallways. Furthermore, for many this is one of the few consistent opportunities among the

Alex Zhornitskiy

AZhornitskiy@mednet.ucla.edu

1 Department of Internal Medicine, Hospitalist Services, Ronald Reagan UCLA Medical Center, Los Angeles, CA, USA

2 Gastroenterology Fellowship Program, Vatche and Tamar Manoukian Division of Digestive Diseases, Ronald Reagan UCLA Medical Center, Los Angeles, CA, USA

3 Medical Service, West Los Angeles VAMC and Departments of Medicine and Surgery, David Geffen School of Medicine at UCLA, Los Angeles, CA, USA myriad of responsibilities available to strengthen and expand medical knowledge. Although physicians are well versed on presenting patient information to one another, few in medicine have actually received any type of training on giving an hour-long talk; the result is presentations that politely stated are of variable quality. While there are a multitude of factors that go into making a talk memorable, they can be narrowed down into four categories: making a good first impression, the effective use of PowerPoint, the successful delivery of information, and meticulous preparation.

\section{First Impressions Are Key}

First impressions matter. Not only can this be attested to anecdotally in personal interactions, but this has also been confirmed in studies [2]. Medical talks are no different. The first impression in this setting is essential to convincing a group of your peers to actively listen to your hour-long presentation among a cacophony of distractions. While it may seem obvious, being audible to the entire audience and confirming this at the start is crucial. Given that these talks occur amidst countless different sounds including buzzing pagers, chiming phones, the crunching of salads, and murmured comments, being heard can truly be a challenge and should be confirmed before proceeding further. Upon establishing that you are heard clearly, one should delineate a tangible reason for why this topic is important and needs to be discussed [3]. After all, if you do not seem interested in the topic, why should the audience be? Clarifying this early while identifying the topic at hand will provide a rationale for the audience as to why they should invest their time 
listening and enable them to "tune in" rather than simply perusing applications and games on their phone. Lastly, once it has been established what to expect from the lecture, take the time to present $3-5$ pieces of information that you expect the audience to learn or better understand by the end. This can be presented as a slide entitled "Objectives" and should be revisited regularly in order to reinforce these learning points. With these in place, any presentation will be off to a great start with a strong first impression.

\section{Effective Use of PowerPoint}

The great orators in history are not often envisioned standing behind a lectern with the glow of PowerPoint slides behind them. Nevertheless, PowerPoint usage is virtually universal in modern-day presentations, with medical talks being no different. Using slides to your advantage, but also not allowing them to take the attention off you as the presenter, can be a fine line to walk. Slides should highlight only the most pertinent information and assist in visually depicting your presentation. That is it. Text should be limited to 4 to 6 lines per slide with under 10 words per line. Clashing, garish colors, large blocks of text, nonstandard fonts, small type size, and intricate diagrams should all be avoided, but are common errors that constitute the dreaded "busy slide." These slides are not only confusing, but as the audience attempts to decipher them, their attention is shifted away from whom the attention should be rightly focused on: you, the presenter. One specific way of combating this is by having information appear point by point to accompany what you are discussing. An audience will naturally read what is presented on a screen. Limiting what is shown prevents the audience from reading ahead and limits confusion regarding statements visually presented that have not yet been discussed, thus retaining focus on what the presenter is saying in the moment.

\section{Delivering Information}

The success of a medical talk is highly dependent on the presenter, since one's ability to convey information and retain interest will be a core determinant of the success of a presentation. While it is commonly noted that the mean attention span is limited to $15 \mathrm{~min}$, it has been suggested that this is actually highly dependent on the presenter [4]. Ultimately, while one's audience may learn differently, the uniting feature to retaining information is through encouraging active learning [5]. Creating opportunities for active learning through group problem solving, questions embedded in the presentation, or requiring audience interaction are key features missing from some medical talks, and not used enough in others. Within the discussion of delivering information, it is also important to delineate how much information a presenter is attempting to cover. While it is commendable when presenters endeavor to maximize the amount of knowledge that they attempt to teach others, it is also often wholly unrealistic to discuss a broad topic such as hepatology within the confines of an hour. It is incumbent on the presenter to deliver a digestible quantity of information that will facilitate maximal learning.

\section{Preparation}

Lastly, the final key to delivering information is through preparation. Since GI fellows are relatively inexperienced with public speaking, it is common to appear ill-prepared or nervous. There is nothing like halting speech patterns, a wavering voice, or anxious facial expressions and body language to communicate that you are not comfortable with your presentation, which in turn will decrease your effectiveness as a speaker. One of the best ways to overcome this angst, gain confidence, and master your material is to thoroughly rehearse your talk in full and out loud prior to the actual event. Consider even soliciting feedback from colleagues to ensure that the presentation is truly concise, at the appropriate level for the audience, and has a logical flow. Also, ensure that there are no surprises well beforehand: do not be late/show up early and check out the venue, check on the format (e.g., 4:3 vs. 16:9) of the projector/display, and load your presentation in advance on the presentation computer. Few are born great speakers, with the statement "practice makes perfect" being surprisingly accurate.

\section{Conclusion}

Although education consists of a multitude of pertinent topics related to discussing and presenting information, little or no training occurs on how to give a good medical talk, despite being regularly requested to do so. These "secrets" are by no means an exhaustive list, and presenting is an art with subtle adjustments at times needed to account for audience, topic, allotted time, and even location. Since the ultimate goal is to teach our colleagues, these suggestions will help one confidently, and effectively, present their next medical talk.

\section{Key Points}

- Giving medical talks is a part of routine medical training and practice, yet there is little no formal education on the topic.

- Delivering a great medical talk stems from creating a good first impression, effective use of PowerPoint, impactful delivery of information, and preparation. 


\section{References}

1. Murre JM, Dros J. Replication and analysis of Ebbinghaus' forgetting curve. PLoS One.. 2015;10:e0120644. https://doi. org/10.1371/journal.pone.0120644.

2. Gilron R, Gutchess AH. Remembering first impressions: effects of intentionality and diagnosticity on subsequent memory. Cogn Affect Behav Neurosci.. 2012;12:85-98.

3. Berkhout JJ, Helmich E, Teunissen PW, van der Vleuten CPM, Jaarsma ADC. Context matters when striving to promote active and lifelong learning in medical education. Med Educ. 2018;52:34-44.
4. Bradbury NA. Attention span during lectures: 8 seconds, 10 minutes, or more? Adv Physiol Educ. 2016;40:509-513.

5. Teunissen PW, Scheele F, Scherpbier AJ, et al. How residents learn: qualitative evidence for the pivotal role of clinical activities. Med Educ. 2007;41:763-770.

Publisher's Note Springer Nature remains neutral with regard to jurisdictional claims in published maps and institutional affiliations. 